\title{
EINSTEIN Y LOS TIEMPOS: LA VERSIÓN DE ALAN LIGHTMAN
}

Einstein and time: Alan Lightman version

\author{
Alí Viquez Jiménez*
}

\section{RESUMEN}

Este ensayo estudia las relaciones entre las concepciones del tiempo y las posibilidades de la felicidad humana que se describen en la novela del físico Alan Lightman titulada Einstein's Dreams.

\section{ABSTRACT}

This paper studies the relationships between the concepts of time and the possibilities of human happiness that are described in the novel by physicist Alan Lightman titled Einstein's Dreams. 


\section{Introducción}

Al terminar la primavera de 1905, Albert Einstein realiza la primera de las propuestas teóricas con que se funda la relatividad. Es un joven veinteañero, está casado y tiene un hijo pero no se relaciona demasiado con su familia, trabaja en una oscura oficina de patentes, vive en una ciudad muy pacífica a los pies de los Alpes... Mi descripción es vaga a propósito: busca retomar el tono con que Alan Lightman escribe una novela, Einstein's Dreams (1993), en la que aborda la vida de Einstein durante esa maravillosa temporada en Berna, cuando una imaginación genial consiguió echar las raíces de lo que sería una nueva visión del mundo en el campo de la física. Pero no se trata de una biografía novelada, porque el propósito de Lightman no es dar cuenta tanto de lo que ocurre en la vigilia como de lo que pasa durante los sueños de Einstein. El texto se dedica a proponer una serie de versiones de la naturaleza del tiempo con las que el personaje de Einstein sueña. Una de ellas dará lugar a la relatividad... Por cierto, no se nos indica claramente cuál de todas: será, en apariencia, la responsabilidad del lector el determinarlo; queda en sus manos escoger el sueño que se impone en la mente del personaje como aquel que consigue dar la versión del tiempo que realmente opera en nuestro universo, de acuerdo con la relatividad.

La vaguedad de la mayoría de las informaciones que sobre el mundo narrado proporciona el texto es notoria: hay muchos más nombres de lugares que de personajes, quienes se identifican sólo por su género, por su apariencia externa, por su oficio o por su pertenencia a algún grupo; eso sí, con frecuencia se nos informa de su estado anímico, aunque expresado de forma muy general, sin detalles. Fuera de Einstein y sus allegados, que aparecen solamente en ciertos pasajes limitados del texto, no existen personajes propiamente individualizados que se mantengan a través de la narración: los protagonistas de cada sueño difieren y la novela da cuenta de treinta sueños en total, lo que da lugar a una multitud de personajes ${ }^{1}$. El onirismo se traduce en una especie de velo que lo cubre todo y sólo nos permite vislumbrar el mundo narrado.

Ese tránsito por los sueños de Einstein tiene en realidad un protagonista no humano: es el tiempo mismo. Mejor si lo decimos en plural: los tiempos. Si a los seres humanos que habitan en los sueños del joven y tímido físico apenas los entrevemos, a los tiempos que modelan los mundos soñados sí que los podemos conocer con claridad. Son los diversos conceptos de tiempo imaginados los que determinan cómo son las vidas de los seres humanos en esos mundos que la novela presenta como resultado de la actividad onírica de Einstein. Y esos tiempos no son esquivos ni se describen tras un velo de misterio: cada uno de los treinta episodios hace explícita la versión del tiempo que preside el mundo con que Einstein sueña.

Esta novela no se basa en las ideas que el Einstein histórico hubiera podido barajar efectivamente acerca de la naturaleza del tiempo. Es completamente especulativa: se permite imaginar posibilidades que pudieron cruzar por la mente del personaje durante el periodo en que se gestaba en él la idea del tiempo que da lugar a la relatividad. En ese sentido, estamos ante un Einstein claramente ficcional, lo que no impide que el texto elabore una cierta propuesta psicológica acerca del personaje histórico valiéndose de este ente ficcional. Volveré sobre algunos pormenores de esta cuestión.

Mi propósito en este ensayo es el resaltar y describir la estrecha relación que se establece en este texto entre las diversas versiones del tiempo y los estados de ánimo que se producen en los personajes que habitan los mundos donde se dan esas versiones. Cada mundo tiene un tiempo diferente, y en ese mundo se puede ser alegre o depresivo, pacífico o iracundo, tranquilo o nervioso, etcétera. Espero comprobar que todos los mundos se pintan con algo en común: en ellos el tiempo ocupa el lugar que hubiera ocupado Dios en una versión religiosa del universo. No que aquí se elabore una visión de los tiempos como seres dotados de una voluntad personal, al estilo del Dios de la mayoría de las 
religiones; más bien, se trata de que el tiempo es el factor determinante a la hora de establecer las posibilidades vitales de los seres humanos. Estamos hechos, ante todo, de tiempo; nuestras vidas serán el resultado de muchos factores, pero el del tiempo es el primordial, al que se pliegan los demás elementos que nos constituyen. El tiempo es pues (y es en este sentido que lo comparaba con Dios) el eje a partir del cual se han creado el mundo y la vida humana, y el éxito o el fracaso emocional de esta depende de él en gran medida. El análisis pormenorizado que sigue buscará comprobar lo anterior ${ }^{2}$.

\section{Un prólogo, tres interludios y un epílogo}

El punto de partida es el mundo en el que habita el personaje de Einstein. Este se aborda en los cinco pasajes que he citado en este subtítulo. Los sueños propiamente se exponen con las fechas de las noches en que Einstein los soñó, y van del 14 de abril al 28 de junio de 1905 (algunas noches se omiten).

Para ser más precisos, habría que decir que el prólogo y el epílogo nos ofrecen el punto de llegada de la novela, puesto que se ocupan de narrar lo que ocurre una vez que Einstein ha tenido todos los sueños que se narran ordenados por fecha, es decir, cuando el personaje ya ha soñado y escogido una versión sobre el tiempo: "Out of many posible natures of time, imagined in as many nights, one seems compelling." (Lightman, 1993: 15) Llama la atención que tanto el prólogo como el epílogo dan cuenta del paso del tiempo minuciosamente: el primero nos avisa que son las seis, y transcurren diez minutos en los cuales amanece y un Einstein muy fatigado recuerda vagamente que vivió esa primavera soñando con mundos diversos; el segundo retoma la narración de ese mismo día, desde las ocho de la mañana, cuando Einstein se despereza; nos informa que a las ocho y cuatro entró la mecanógrafa y a las ocho y seis él le entregó su manuscrito con el documento que revolucionará la física. El tiempo, pues, con su detallado transcurrir, se plantea desde el principio de la narración y hasta su final como protagonista. Sólo una cita entre muchas que podrían hacerse, y que demuestra que la narración se centra en su inexorable paso: "Minute by minute, new objects gain form. Here, a brass wastebasket appears. There, a calendar on a wall. Here, a family photograph, a box of paper clips, an inkwell, a pen. There, a typewriter, a jacket folded on a chair. In time, the ubiquitous book-shelves emerge from the night mist that hangs on the walls." (Lightman, 1993:13) Un implacable tiempo que atraviesa todos los hechos narrados.

En los interludios se introduce al personaje de Besso, amigo de Einstein, y se nos hace ver cómo la vida del gran genio de la física tenía tal inclinación hacia su interior que resultaba muy difícil asomarse a ella. Besso sin embargo parece saber más que la propia esposa de Einstein, Mileva, quien no tiene peso alguno en la narración. De hecho, los tres interludios nos hablan de episodios entre Besso y Einstein, en los que Mileva y el bebé Hans Albert apenas intervienen. Besso piensa que la vida familiar de Einstein es trabajosa, dado el carácter esquivo de este. Einstein no sale con Mileva, y hasta efectúa confesiones que indican que en lugar de esposa quiso hacerse de una mucama: "He once admitted to Besso that he had hoped Mileva would at least do the housework, but it hasn't worked out that way. The unmade bed, the dirty laundry, the piles of dishes are just as before. And there have been even more chores with the baby." (Lightman, 1993: 115) Con esta displicencia de Einstein hacia su familia, contrasta la actitud de gran preocupación que ha sabido mostrar en otro momento hacia su amigo y compañero de estudios: "Besso's father died suddenly, in his late forties. Besso, who had never gotten along with his father, felt griefstricken and guilty. His studies came to a halt. To Besso's surprise, Einstein brought him into his lodgings and took care of him for a month." (Lightman, 1993: 113)

Ahora bien, en mi opinión no se trata aquí de un cuadro como el que se ha señalado en relación con el príncipe Hamlet, quien tiene una mejor relación con su confidente Horacio que con Ofelia, lo que puede apuntar hacia un 
homosexualismo latente. Creo que Einstein ha sido absorbido, durante estas fechas, por su trabajo, y encuentra en Besso (que no en Mileva o en Hans Albert) a alguien con la formación necesaria para entender cuál es la orientación de su quehacer en la física. De hecho, las conversaciones con Besso no incluyen ninguna información personal o íntima: lo poco que Einstein dice tiene que ver con física. Además, nos enteramos de que Besso es quien busca la compañía de Einstein, y no a la inversa, y esto porque piensa un poco paternalmente en su amigo, pese a conocer su autosuficiencia: "Besso hands Einstein a sandwich and a beer. He feels slightly guilty for asking his friend to take him along on this Sunday afternoon. Einstein was planning to go fishing alone, in order to think" (Lightman, 1993: 165).

Además de esquivo en general, distante con su familia y absorto en el trabajo, Einstein aparece como un personaje generoso, dispuesto a colaborar con ideas valiosas en los inventos cuyas patentes le toca registrar como parte de su trabajo de burócrata en Berna, Suiza, y $\sin$ cobrar ni obtener reconocimiento. $\mathrm{Su}$ capacidad para la alegría está toda enfocada en el éxito que pueda obtener con su trabajo en la física, y no en los inventos más prácticos. Sus intereses abarcan el ámbito de lo teológico, que considera entrelazado con su trabajo en la ciencia: desea acercarse al pensamiento de Dios. Curiosamente, cuando ha terminado de pergeñar su teoría, lo domina una sensación de vacío. La culminación de su trabajo tampoco llena su vacío existencial. Volveré sobre esto en las conclusiones de este ensayo.

\section{Los tiempos de la desdicha}

Cada concepto del tiempo con el que Einstein sueña un mundo crea tendencias hacia la felicidad o la infelicidad de los que habitan en este. Repasaré ahora aquellos que producen la desdicha, al menos como tendencia dominante, dado que tampoco puede decirse que se excluya por completo en todos estos mundos la posibilidad de ser feliz. Me encargaré de matizar cada caso. Además, no pienso abstenerme a la hora de señalar en cuáles casos se detecta, en mi opinión, una construcción inconsistente del mundo narrado.

a) En el eterno retorno nietzscheano (14 de abril de 1905), hay lugar para lo bueno y lo malo en las vivencias humanas, pero únicamente los infelices saben que están condenados a repetir sus infortunios. La sabiduría llega sólo a quienes sufren. Curiosamente, y aunque Nietszche no se menciona (pero sí se evidencia), el mundo que el filósofo alemán parece haber imaginado para comprometer a sus seguidores con una vida plena (pues hemos de ser felices, ya que esta vida, y no otra, viene a ser nuestra eternidad, por la vía de una repetición idéntica, circular, infinita), no ofrece tales resultados positivos en la versión que nos da Lightman. Aquí sólo se puede ser feliz si no se es sabio, idea muy poco afín con el pensamiento nietszcheano.

b) En un tiempo que permite retornos involuntarios de algunas personas (16 de abril de 1905), estos individuos se convierten en penosos viajeros, agobiados por el deseo de volver a su época de origen, cosa que no pueden controlar. Viven condenados a la soledad, intentando por todos los medios no intervenir en el tiempo pasado a que han ido a parar, por miedo de dar lugar a paradojas como la del nieto que mata a su abuelo antes de que este haya engendrado a su padre, un lugar común de la ciencia ficción.

c) El mundo del 19 de abril de $1905 \mathrm{se}$ concibe con un tiempo tridimensional, un poco a la manera borgesiana de "El jardín de senderos que se bifurcan", sólo que aquí se trata de trifurcaciones: hay tres dimensiones del tiempo, así como hay tres dimensiones espaciales. Esto quiere decir que se pueden tomar tres caminos distintos a cada momento, lo que implica una multiplicación de las trifurcaciones temporales. Todas las tres (por tres 
por tres por tres...indefinidamente) posibilidades transcurren paralelamente. Esto complica las decisiones humanas a un grado tan vertiginoso que las convierte en irrelevantes (toda decisión se ha tomar en algún mundo) o caóticas (toda decisión existe junto con su contrapartida).

d) En un mundo en el que coexisten el tiempo objetivo, mecánico y medible en el reloj, y el tiempo subjetivo, ligado al propio cuerpo y a sus impulsos únicamente (24 de abril de 1905), se producen tanto la alegría como la desesperación. Esta última, por la imposibilidad de conciliar objetividad y subjetividad. $\mathrm{Si}$ se mantienen los tiempos separados, es posible ser feliz, pero si se juntan, la verdad que produce cada uno entra en conflicto con la otra. Se trata de que el curso objetivo del tiempo no es compatible con su vivencia subjetiva. Ahora bien, lo curioso aquí resulta la existencia de algunos seres humanos que son capaces de renunciar a la subjetividad temporal y se rigen únicamente por el tiempo mecánico y objetivo, donde -no queda claro de qué manera -- pueden existir.

e) El mundo en el que el tiempo fluye más lentamente cuanto mayor sea la distancia desde el centro de la tierra ( 26 de abril de 1905) funciona de acuerdo con una marcada jerarquización social de sus habitantes: "Height has become status." (Lightman, 1993: 39) Los que tienen un lugar más alto en la escala social lo tienen literalmente en sus espacios vitales: residen en casas en lo más alto que se pueda, con el fin de envejecer más lentamente. Pero hay un problema que termina por arruinar la felicidad de los adinerados: tanta preocupación por no envejecer aprisa más bien desemboca en formas de vida poco saludables, y la paradoja no se hace esperar: "At length, the populace have become thin like the air, bony, old before their time" (Ligthman, 1993: 42). f) El mundo con un tiempo en el que el pasado y el futuro se entrelazan de modo tal que las causas y los efectos no se pueden determinar ni mucho menos prever (3 de mayo de 1905) da lugar tanto a la desdicha de algunos como a la felicidad de otros. Las personas se ven obligadas a vivir cada momento sin poder explicárselo como una consecuencia de un hecho pasado, ya que eventualmente es el futuro el que se traslada al pasado, y viceversa. Esto crea la frustración de los científicos: "Their equations become justifications, their logic, illogic. Scientists turn reckless and mutter like gamblers who cannot stop betting. Scientists are buffoons, not because they are rational but because the cosmos is irrational. Or perhaps it is not because the cosmos is irrational but because they are rational. Who can say which, in an acausal world?" (Lightman, 1993: 52)

g) Un mundo en el que el tiempo pasa sin que ocurra casi ningún acontecimiento (4 de mayo de 1905) viene a ser el mundo de la frustración del deseo. No es posible anhelar cambios, porque estos no se dan sino muy lentamente y muy rara vez. Así, todos están condenados al sufrimiento, si bien aquellos cuyo deseo es menor carecen de la conciencia de sufrir.

h) Un tiempo cuya textura es pegajosa produce la infelicidad general (10 de mayo de 1905). Se trata de un curioso mundo en el que la gente o los lugares se pueden quedar adheridos a un cierto momento, y así el tiempo deja de transcurrir para ellos. Esto los aleja a los unos de los otros (nunca se detienen todos en el mismo momento), por lo que su terrible soledad se traduce en desdicha. Lightman lee aquí con un dejo de ironía aquello de "ten cuidado con tus sueños, porque podrían cumplirse": el deseo de mucha gente de detener el tiempo en un momento de felicidad redundaría en el aislamiento; sólo el tiempo que transcurre nos permite compartir la vida. 
i) Un mundo en el que la segunda ley de la termodinámica se ejecuta al revés es el descrito el 11 de mayo de 1905. Esta ley, por medio del concepto de entropía, nos dice que en nuestro mundo todos los sistemas físicos en aislamiento incrementan su desorden con el paso del tiempo; en este mundo soñado por Einstein ocurre exactamente lo contrario. Aquí también la infelicidad abunda, pues el orden que se impone forzosamente resulta intolerable, sobre todo en primavera. Resalto sin embargo una cuestión: queda claro que el mundo donde se cumple la segunda ley de la termodinámica, el nuestro, también resulta intolerable. Cuando los filósofos del mundo soñado en esta fecha reflexionan que sin esta "anti-entropía" el futuro y el pasado resultarían indiscernibles, no nos están diciendo algo diferente de lo que pasa en nuestro mundo, con la única salvedad de que la flecha del tiempo se ha invertido. Ello no parece incidir, ni negativa ni positivamente, en la vida de las personas, cuya tendencia a la tristeza no decrece por el hecho de no tener que preocuparse por hacer la cama o barrer el polvo, ya que la naturaleza se encarga.

j) El tiempo detenido es el del 14 de mayo de 1905. Pero este tiempo detenido sólo está totalmente detenido en su centro, que es un centro físico: cuanto más se aleje alguien de él, más rápido transcurrirá su tiempo. Muchos lo hacen, por la sencilla razón de que sin tiempo no hay vida. Esta, que se describe como "una copa de tristeza", sólo puede beberse cuando el tiempo transcurre. Lo que no quita que aparezcan personajes deseosos de congelar la vida en un instante y quedarse clavados como una mariposa en su caja: "Life is a vessel of sadness, but it is noble to live life, and without time there is no life. Others disagree. They would rather have an eternity of contentment, even if that eternity were fixed and frozen, like a butterfly mounted in a case." (Ligthman, 1993: 85-86) Y aunque el sueño del día siguiente (15 de mayo de 1905) se plantee como si se hubiera imaginado un mundo diferente (uno sin tiempo), se trata de hecho de lo mismo, sólo que en este caso no hay manera de alejarse de un centro para que el tiempo sí transcurra. Lo que pasa entonces es que no hay vida; tan sólo una serie simultánea de imágenes. Diré que este es un mundo imaginado con cierta debilidad : la mera enunciación de una serie de imágenes implica la presencia de una sucesión temporal. El hecho de que exista, por ejemplo, la imagen de una mujer que debe hablar con su marido, hace obligatorio que alguna vez haya transcurrido el tiempo: ¿cómo podría haberse convertido en la mujer de su marido si no? Lo cierto es que el sueño de este 15 de mayo sirve para demostrar que podemos imaginar mundos con tiempos muy diversos (es lo que hace esta novela), pero un mundo sin tiempo alguno resulta sencillamente inimaginable. Puede enunciarse (es lo que en el fondo consigue hacer Lightman), pero, apenas se concreta su descripción, esta resulta insostenible.

k) El mundo descrito con un tiempo que transcurre más lentamente cuanto mayor sea el movimiento es el del 29 de mayo de 1905. Esto ha creado una competencia por ver quién se mueve más deprisa: esa persona tendrá más tiempo. Y el resultado de tanta rivalidad termina por ser la frustración, la necesidad de moverse a toda costa amarga la vida de las personas; sólo quienes renuncian a la competencia pueden aspirar, si no a la felicidad, al menos a la resignación. Este sería el mundo en que se daría (aunque Lightman no lo dice abiertamente) la famosa paradoja de los gemelos implicada en la relatividad: si dos gemelos se separan y uno de ellos permanece en la tierra y el otro emprende un viaje cercano a la velocidad de la luz 
y regresa, al cabo de (digamos) veinte años para el que se quedó habrá pasado sólo un año (digamos) para el que se fue y regresa. Si esto indica que este es el sueño que mejor se aproxima al mundo que la relatividad describe, es algo que yo sospecho, y esta opinión también es la de Wallhead (2005: 187). Subrayo el hecho de que se trata de uno de los mundos de la desdicha generalizada: si es cierta la elección de este sueño como el que da lugar a la relatividad, ya sabemos lo que propone Lightman (o más exactamente, su personaje Einstein) respecto al grado de felicidad del mundo en que vivimos: es muy bajo.

1) En el mundo del 3 de junio de 1905, la gente vive sólo un día. Esta brevedad de la existencia se traduce en una gran incapacidad para concluir ningún proyecto, lo que produce frustración. De una manera que no se explica (pues, ¿con qué tiempo habría podido inventarse la escritura?), existen libros que dan cuenta de cómo en el mundo se suceden las estaciones, pero nadie ha podido vivir lo suficiente como para experimentar el paso del verano al otoño. La fugacidad atropella a la felicidad humana.

m) El tiempo es un sentido, como la vista y el olfato, en el mundo del 5 de junio de 1905. Por ello, existe una gran incertidumbre acerca de su existencia real, fuera de la percepción humana. Si bien la limitante frustra el deseo de conocimiento humano (no hay filosofía y ciencia, sino solamente estética), en este caso no se señala la desdicha como una consecuencia demasiado marcada, salvo quizás en lo que compete a una minoría de "sordos del tiempo". Estos pocos nacen sin el sentido del tiempo y ello los lanza al abismo de la incomunicación, pues el lenguaje verbal sólo se puede adquirir si se tiene noción del tiempo.

n) El mundo del 9 de junio de 1905 tiene la particularidad en el libro de que su peculiaridad no es el concepto de tiempo, sino el que en él no existe la muerte como fin inevitable de la existencia. El tiempo es el mismo que en nuestro mundo. La vida humana es lo diferente, porque no tiene fin, a menos que se cometa suicidio. Esto crea un estado de incompletud y una falta de libertad generalizadas, dado que cada ser humano se debe a los otros, en la medida en que estos otros ya han pasado por todo aquello por lo que se puede pasar en la vida, habida cuenta de la enorme prolongación de esta. Algunos viven su existencia frenéticamente, intentando acumular experiencias, mientras que otros posponen todo, pensando que ya habrá tiempo para hacerlo. En ambos casos, sólo la muerte puede liberar al ser humano de un pasado que constituye una carga inmensa: curiosamente, son las vidas eternas de los otros las que resultan insoportables. Cuando uno que otro decide suicidarse, lo hace para librarse de estos otros, el infierno sartreano multiplicado por la eternidad. Pero la mayoría elige vivir en ese infierno, al cual se acostumbran, como a una inevitable infelicidad.

o) El mundo del 10 de junio de 1905 presenta un tiempo que, aunque existe, no se puede medir. Esto crea un sinnúmero de malentendidos pues las personas no logran ponerse de acuerdo sobre cómo organizar sus vidas conjuntamente. Algunos logran dejarse llevar tranquilamente por el vaivén inconmensurable de este mundo sin tiempo cuantificable; otros, más bien están dispuestos a ofrendar sus vidas con tal de medir el tiempo, empresa fatal: "Some people attempt to quantify time, to parse time, to dissect time. They are turned to stone. Their bodies stand frozen on street corners, cold, hard, and heavy. In time, these statues are taken to the quarryman, who cuts them up evenly in equal sections and sells them for houses when he needs the money" (Lightman, 1993: 146). 
p) El mundo sin futuro es el del $11 \mathrm{de}$ junio de 1905. No se trata sólo de que no se lo pueda percibir, sino de que de hecho el futuro no existe: "In this world, time is a line that terminates at the present, both in reality and in the mind" (Lightman, 1993: 149). No obstante esta aseveración, la descripción del mundo me hace pensar que (como ya he detectado en otras tres ocasiones) se trata de un enunciado que luego es contradicho por la narración misma de ciertos acontecimientos: la inexistencia del futuro no sólo subjetivamente (lo cual es posible) sino también objetivamente resulta insostenible. Se trata entonces de que la gente no tiene conciencia de la existencia del futuro, pero en la medida en que el tiempo transcurre, lo hace desde el pasado hacia el futuro, el cual sí existe. Son infelices quienes necesitan cambiar su desdichado estado actual, pues carecen de la esperanza de un futuro distinto. No queda claro si estos son mayoría.

q) En el mundo del 17 de junio de 1905 el tiempo es levemente discontinuo. Tan levemente que en la cotidianeidad de los seres humanos nadie lo percibe como discontinuo. Pues, además, ya que las vidas de los personajes también se detienen por ínfimos instantes en el tiempo, para ellos, en la práctica, no hay tal discontinuidad. O mejor diríamos que no son conscientes de que el tiempo se detiene por momentos, pero en algunas ocasiones sí sufren las consecuencias de ciertos desajustes en el paso del tiempo. Las discontinuidades pueden dar lugar a pequeños desplazamientos. Se nos da sólo un ejemplo, y es de un caso en que el desajuste produjo la infelicidad de una pareja. No se generaliza, pero creo significativo que el caso comentado se caracteriza por el desamor y el infortunio.

r) El mundo del 18 de junio de 1905 ofrece un panorama político sombrío. En este caso, la medición mecánica del tiempo, su objetivización forzosa y temida a la vez, tiene por consecuencia la limitación de la libertad para vivir. En el fondo, se trata de una alegoría de la organización política que ha dominado efectivamente nuestro mundo, imponiendo por sobre otras vivencias subjetivas del tiempo (los latidos del corazón, el ritmo del sueño, la recurrencia del hambre...), la tiranía del reloj mecánico, que "hace correr el tiempo" igual para todos. No extraña que el Gran Reloj, objeto de culto y de frustración a la vez (pues es quien manda y quien crea la desdicha con su tiranía) se encuentra en Roma, la capital de ese gran proyecto político disfrazado de religión que se llama catolicismo.

s) En el mundo del 20 de junio de 1905 existen una gran cantidad de tiempos locales. Tan locales que dos relojes nunca marcan exactamente el mismo tiempo, porque no pueden estar exactamente en el mismo lugar. Cada ciudad consigue organizar su vida más o menos sincronizadamente, pero cuando las distancias crecen ello es imposible: las variaciones entre una ciudad y otra son tales que viven aisladas entre sí. Los viajeros que se aventuran a ir lejos no consiguen regresar al punto de partida, porque el tiempo en cada sitio es diferente. Ello produce aislamiento tal, que en el fondo las personas son infelices, porque sus vidas no llegan a comunicarse. Este es un mundo de solipsismo. Señalo, además, que este carácter local del tiempo puede verse como una evocación de la relatividad temporal, lo que abre la puerta para dudar de si este también se podría considerar un sueño que contribuya a la creación de la teoría de Einstein. Si bien es cierto el texto nos asegura que uno solo de los sueños es el elegido ("one seems compelling”), este también podría haber iluminado parte del camino de la reflexión einsteiniana.

t) El mundo en que el futuro está completamente predeterminado es el del 
22 de junio de 1905. La libertad humana es inexistente, lo que crea una enorme indiferencia de los personajes hacia sus propias vidas, que viven sin poder modificar. Nadie tiene voluntad; cada cual sólo se deja llevar como si todo diera igual: "In a world of fixed future, life is an infinite corridor of rooms, one room lit at each moment, the next room dark but prepared. We walk from room to room, look into the room that is lit, the present moment, then walk on. We do not know the rooms ahead, but we know we cannot change them. We are spectators of our lives." (Lightman, 1993: 182) La ausencia del bien y del mal, tema que bien podría haber dado para mucho más, apenas y se explota: limitación explicable en un texto que no pretende profundizar en la ética sino en la física.

u) El 25 de junio de 1905 da lugar a un sueño en el que el tiempo se asemeja a una luz que rebota entre dos espejos, lo que provoca una cantidad infinita de variaciones, como las que tiene la luz al transitar reflejándose así. La infelicidad se produce por la incapacidad humana de tomar decisiones definitivas, pues el tiempo multiplica los dilemas de una forma vertiginosa.

v) El mundo del 27 de junio de 1905 es en realidad dos mundos. En el primero, el pasado es fijo e inmutable, de modo que nada puede cambiarlo. Se nos presenta el caso de alguien perseguido por un hecho del pasado que arruina su vida. No poder mirar al pasado con ojos distintos produce una gran infelicidad. En el segundo, el pasado cambia como un caleidoscopio cada vez que se mira hacia él. Por consiguiente, el pasado apenas existe, se torna sumamente quebradizo. La felicidad aquí parece ser más posible, pero también es frágil.

w) El 28 de junio de 1905 se produce el último de los sueños de Einstein. Lightman se permite elaborar aquí el menos racional de estos: imagina un mundo en el que una bandada de ruiseñores es el tiempo: "Because this flock of nightingales is time. Time flutters and fidgets and hops with these birds. Trap one of these nightingales beneath a bell jar and time stops. The moment is frozen for all people and trees and soil caught within." (Lightman, 1993: 197-198) Esto acarrea la frustración general, pues todos desean atrapar uno de estos pájaros para poder detener el tiempo, pero son demasiado lentos para ello. Sólo los niños son capaces, pero estos no quieren detener el tiempo, sino que son felices viéndolo pasar aprisa. Y cuando algún adulto, rara vez, logra hacerse de un ruiseñor, este momento atrapado muere, como lo haría un pájaro al que le han cortado las alas. Lightman insiste así en la imposibilidad de detener el tiempo, aunque este sea nuestro deseo, mediante la metáfora del ruiseñor que muere cuando se le retiene.

\section{Tiempos felices}

Su número es menor, pero existen. Verdad de Perogrullo (¡ay!) para la literatura, que el texto de Ligthman también nos confirma, con el peculiar recurso de la imaginación de un genio de la física. Ahora bien, su número quizá no es muchísimo menor: ya comentaré en las conclusiones algo al respecto.

a) En el eterno retorno nietzscheano, como ya lo dije, los menos inteligentes consiguen ser felices (14 de abril de 1905*).

b) El mundo del 24 de abril de $1905^{*}$ permite la coexistencia del estado disfórico con el estado eufórico. Aquellos que se dedican únicamente al disfrute del tiempo subjetivo consiguen ser felices.

c) En el mundo de las grandes diferencias sociales del 26 de abril de 1905*, logran ser dichosos quienes renuncian al deseo de elevarse por encima de los otros. 
d) El mundo del 28 de abril de 1905 es el del tiempo absoluto. Sin mencionar a Newton, se construye un mundo en el que opera un tiempo que es un "sensorium Dei". No falta la inferencia religiosa: "Nothing could be universal and not be divine. All absolutes are part of the One Absolute. And wherever absolutes, so too time. Thus the philosophers of ethics have placed time at the center of their belief. Time is the reference against which all actions are judged. Time is the clarity for seeing right and wrong." (Ligthman, 1993: 45) Esta claridad ofrece un consuelo, si bien limita la libertad humana, como lo hace en efecto cualquier visión deísta del mundo. Por ello es importante subrayar que este mundo no está pleno de dicha propiamente: "A world in which time is absolute is a world of consolation" (Lightman, 1993: 47).

e) El mundo en que presente y futuro se entrelazan arbitrariamente, del 3 de mayo de 1905*, les da felicidad a los artistas, que aman lo imprevisto y la conducta irracional de todo cuanto les rodea y de ellos mismos, y a aquellos que aprenden a vivir disfrutando únicamente del momento presente. Además, reina la sinceridad con que se ejecutan los actos impulsivos, lejos del cálculo y la manipulación.

f) En la misma línea que el anterior, el 8 de mayo de 1905 se concibe un mundo en el que espacio para la felicidad es posible por causa de la adhesión al "carpe diem". Aquí, en realidad no se elabora una visión de tiempo peculiar, lo distinto es que se conoce con exactitud la fecha del fin del mundo. Puede sorprender que este sea uno de los "tiempos felices": la versión de Lightman es tal que, lejos de producirse la desesperación entre las personas, se incrementan la igualdad y la solidaridad, pues todas las cosas que diferenciaban y separaban a los seres humanos pierden importancia ante la inminencia del fin. Este llega en medio de la placidez generalizada. g) La inexistencia de la memoria es el rasgo característico del mundo del 20 de mayo de 1905. Esto produce una constante sensación de asombro y novedad en las personas, la cual se traduce en felicidad: cada momento se vive sin que lo opaquen el hábito o la rutina. Es, nuevamente, una versión del "carpe diem". Se presenta, con todo, un lado oscuro: la falta de memoria implica falta de identidad, una existencia un tanto fantasmal, que se remedia parcialmente con el recurso de la escritura. Cada cual lleva el libro de su vida consigo, para repasarlo y saber quién es. Pero parece que los verdaderamente felices son quienes se acostumbran a abandonar el pasado sin preocuparse por lo ocurrido.

h) El mundo del 22 de mayo de 1905 es aquel en donde el tiempo fluye irregularmente, lo que permite a sus habitantes tener casuales visiones del futuro. Este futuro es irrenunciable, pero no todos lo conocen. Entonces, algunos que sí conocen su futuro tienen una vida ordenada y sin riesgos, satisfactoria hasta cierto punto, pues aunque no depara sorpresas sí se sabe hacia dónde se avanza. Otros, conociéndolo también, tratan de cambiarlo, lo que resulta imposible, y para estos el resultado es sombrío. $\mathrm{Y}$ aquellos que no conocen aún su futuro, aguardan -durmiendo lo más posible-a tener la visión que les asegurará el éxito de un determinado proyecto.

i) En el mundo del 2 de junio de 1905, el tiempo fluye hacia atrás. Esto permite a la gente conocer sus vidas completamente, ya que "comienzan" viviendo un futuro en el que tienen recuerdos de lo que ya "pasó". En la medida en que con el envejecimiento la vida tiende a empeorar, la gente suele ser feliz porque avizora en su pasado la oportunidad de mejorar.

j) El mundo del 3 de junio de 1905*, en el que la vida humana es brevísima, ofrece 
una pequeña posibilidad de dicha, en aquellos que tienen la suerte de nacer a la salida del sol, lo que los llena de un cierto optimismo, a diferencia de quienes han nacido en la noche y aprenden a desarrollar el temor de la oscuridad. Estos "diurnos" tienen la confianza de quienes han disfrutado de una juventud "luminosa".

k) El mundo sin futuro del 11 de junio de 1905* deja un espacio para la felicidad de aquellos que no se preocupan por un mañana que no existe y se realizan, como ya hemos visto ocurrir en otros casos, disfrutando el momento presente.

1) En el mundo del 15 de junio de 1905, el tiempo es una dimensión visible, lo que permite a la gente avanzar por ella, o detenerse, como lo harían por un camino. Cada cual avanza sólo si lo desea, y este incremento de la libertad para elegir el momento en que se vive es afortunado. No obstante, señalaré que no queda claro por qué alguien desearía avanzar hasta el momento de su muerte, ni cómo es que aquí (a diferencia de lo dicho ya acerca del tiempo que se detiene) se produce más bien la dicha. En mi opinión, este es el sexto y último de los casos en que la narración presenta debilidades.

m) El mundo de los determinismos del 22 de junio de $1905^{*}$ deja abierta la puerta de que, aunque no existe la libertad, sí puede existir la sensación (falsa) de ser libre, lo que produciría felicidad. Como no es posible cambiar el futuro, en el momento presente las decisiones se tornan antojadizas, pues de todos modos no se es responsable por lo que estas produzcan: ya está todo escrito.

n) Como ya dije, en el mundo del 27 de junio de $1905^{*}$, cuando el pasado se puede cambiar, existe la posibilidad de encontrar una dicha quebradiza. Más concretamente, esto ocurre cuando se transforman los hechos dolorosos por recuerdos que no producen trauma. Este mundo permite la regeneración exitosa del pasado, si bien siempre existe la amenaza de que ese pasado vuelva a cambiar, quizás no para bien. De aquí su fragilidad.

\section{Conclusiones}

a) El texto abierto

No se determina explícitamente cuál de los sueños es el que Einstein elige para crear a partir de él su teoría de la relatividad. Siguiendo a Wallhead, suscribo una fecha (29 de mayo de 1905), pero la discusión no me parece que esté clausurada; he tenido dudas al considerar también posible el mundo del 20 de junio de 1905, pues en este el carácter local del tiempo podría estar evocando (exageradamente) la relatividad temporal.

b) Einstein, el infeliz

El personaje de Einstein se construye como un individuo problemático en relación con su familia, como ya hemos visto. Ahora quiero subrayar que sus problemas van más allá: la física, que le ofrece en principio una compensación a su soledad, no basta sin embargo para curarlo de una sensación de vacío existencial que se subraya al final de la narración: "Einstein walks back to his desk, sits down for a moment, and then returns to the window. He feels empty. He has no interest in reviewing patents or talking to Besso or thinking of physics. He feels empty, and he stares without interest at the tiny black speck and the Alps." (Ligthman, 1993: 202) Creo que es muy importante notar que la motivación de Einstein para emprender su labor en la física tuvo un fundamento que el propio Besso notó contradictorio, lo que explicaría en parte que no obtenga un resultado satisfactorio: Einstein quería acercarse a Dios, comprender el pensamiento divino por medio de la física. Y Besso advertía: "Besso eyes his friend curiously. For such a recluse and an introvert, this passion for closeness seems odd" (Lightman 1993: 62). 
Einstein va tras el conocimiento por un afán de cercanía con Dios, pero en el fondo es un hombre que no desea cercanía con nadie. Esta es una forma de interpretarlo. La otra, que prefiero, es que Einstein trata de acercarse a Dios como un mecanismo de compensación porque no consigue acercarse a ningún ser humano. $\mathrm{Su}$ tragedia personal consiste en que es imposible la cercanía total con Dios, pues la ciencia jamás termina de descubrir la Verdad, escrita así, con mayúscula, tal como estaría en la mente de un hipotético Dios. La sensación de vacío de Einstein es síntoma de que, habiendo conseguido la teoría que tanto anhelaba, esta tampoco le proporciona la Verdad. Dios sigue lejos.

\section{c) Seis sueños problemáticos}

Detecté seis casos en los que la construcción del mundo soñado me parece defectuosa, básicamente porque se enuncia una concepción de tiempo que resulta insostenible una vez que se describe el mundo narrado. Es decir, el tiempo anunciado contradice lo que ocurre en el mundo narrado. En la mayoría de las ocasiones, lo que ocurre es que la idea de que pueda existir un mundo sin tiempo o con el tiempo detenido en cierto momento, es enunciable, pero no sostenible en la construcción del mundo narrado, que es siempre una descripción de hechos que se suceden. Probablemente, la causa profunda de esta insostenibilidad es la incapacidad (señalada por Borges) que tenemos los seres humanos para imaginar una existencia atemporal: el pensamiento mismo es un decurso.

Matizo ahora el párrafo anterior, con la siguiente reflexión: en la lógica de la narración, todos los mundos descritos provienen de sueños de Einstein. Bien cabe entonces que sea el personaje, al soñar, quien procede a imaginar mundos que sólo pueden enunciarse, pero no construirse sin incurrir en la contradicción. Y ciertamente sus sueños no tienen por qué atenerse a las reglas de una construcción lógica. Lo que pasa, por otro lado, al admitir esto, es que si los sueños de Einstein fueran delirios arbitrarios, entonces la novela pierde todo su sentido como un espacio de especulación por parte de un personaje científico, el cual es a las claras su planteamiento fundamental. Aquí no se trata de contar lo que soñó Einstein incluyendo por ejemplo sus pesadillas, sus sueños eróticos o sus fantasías inconscientes: interesan los sueños que pueden aportar en su visión de mundo científica. Por eso sigo pensando que en estos sueños la construcción de los mundos resulta defectuosa.

d) La ciencia y la vida

Esta novela se construye sobre el eje de la relación entre las hipótesis científicas y la resonancia que estas tienen en diversas visiones de mundo. La ciencia física en particular, resulta un espacio de visualización de la vida humana, en cuya descripción se resaltan los aspectos emotivos. Ciencia y vida se conectan de manera tal que ninguna hipótesis científica se crea sin que dé lugar a una visión concreta de la vida, visión que incluye valoraciones éticas y -sobre todo-existenciales.

e) Felicidad y tiempo

Hemos podido comprobar que las diversas concepciones de tiempo dan lugar a la felicidad o a la desdicha de los habitantes de los mundos construidos en la narración. Ahora bien, algunos matices deben explicarse:

Hay casos en los que el tiempo actúa de manera determinantemente positiva o negativa. En estos, no hay lugar para la libertad humana, y los personajes sólo pueden vivir de una forma feliz o infeliz sin que ello esté en sus manos. Son la mayoría; suman veinte, a saber: 16,19 y 26 de abril; 4,8,10, 11, 14, 15 y 29 de mayo; $2,3,5,17,18,20,22,25,27$ y 28 de junio. 
Hay otros casos en los que el tiempo no provoca inevitablemente cierto tipo de vivencias. La libertad humana para tomar un camino que conduce a la felicidad (o no) sí opera en estos. (Esto dio lugar a que estos mundos se incluyeran tanto al repasar los mundos felices como los infelices.) Son minoría; suman once, a saber: 14, 24 y 26 de abril; 3, 20 y 22 de mayo; 9, 10, 11, 15 y 27 de junio.

Como se ve, si se mira a la novela globalmente, hay más probabilidades de encontrar personajes infelices que lo contrario. Pero es significativo que casi siempre la felicidad esté asociada a una actitud concreta: el "carpe diem". Aprovechar el momento, de cualquier manera que este nos llegue según la clase de tiempo en que nos ha tocado vivir, es el secreto (a voces) de la no muy probable y no siempre posible felicidad humana.

\section{Notas}

1. Celia Wallhead (2005: 185) sostiene que el personaje de Einstein incursiona también en algunos de los sueños, aunque no se le identifique con ese nombre. Me parece muy posible, sobre todo en el pasaje en que aparece un físico que ha ganado el Premio Nobel (Lightman 1993: 120-121). Claro que esto equivale a plantear, dentro de la lógica de la narración, que Einstein ya sabía en 1905 que iba a ganar el Premio Nobel. No es tan inverosímil, pero tiene ribetes problemáticos: después de todo, para entonces Einstein era sólo un oscuro empleado de una oficina de patentes. ¿Y cómo sabría además que se lo iban a dar cuando fuese un hombre de mediana edad, que es lo que afirma el texto, y lo que efectivamente ocurrió?

2. Mi agradecimiento al Dr. Manuel Ortega, catedrático de Física de la Universidad de Costa Rica, por su gentil revisión de los aspectos propios de su especialidad que se abordan en este ensayo.

3. Sé que alguna gente piensa que la crítica sólo describe sin juzgar; yo más bien sostengo que es irresponsable por parte de un crítico el autocensurarse cuando sus hallazgos le demuestran debilidades en lo que examina.
4. Identificaré los sueños del mismo modo que en la novela, por la fecha en que Einstein soñó cada uno de ellos.

5. Es posible explicarlo por el hecho de que Nietzsche puede ser el más famoso exponente moderno de la idea del eterno retorno, pero no su autor original. Tal vez por eso Lightman toma esta versión del "eterno retorno" sin mencionar el nombre del filósofo de los grandes bigotes.

6. Este es el primero de los sueños que me parecen un tanto débiles por cuanto su construcción se puede enunciar, pero no se despejan las dudas que surgen.

7. Metáfora de las diferencias sociales sólo hasta cierto punto: es verdad que en nuestro mundo el pent house, que ocupa la cumbre de los edificios residenciales, es la morada de los adinerados. Asimismo, en las empresas, quienes tienen mayor poder también ubican sus oficinas en lo más alto.

8. Tómese en cuenta además que lo que ganaban por residir en las alturas era tan sólo unos pocos instantes.

9. Agrego al margen de este pasaje que Lightman reproduce un cierto lugar común, según el cual los científicos son seres racionales y los artistas no.

10. El segundo, en mi opinión. Véase la nota 6.

11. Tercer caso problemático.

12. Decir esto no implica suponer que en nuestro mundo la naturaleza del tiempo sea perfectamente conocida; lo que ocurre es que en este sueño no se la problematiza.

13. Debo sin embargo matizar esta opinión: el texto de Lightman también se puede abordar enfatizando todo lo que tiene de problematización en aspectos sociológicos. Es, de hecho, el camino que toma Butler (2014): “Thus, Lightman's short stories in Einstein's Dreams shine with allusive glitter and illuminate with poetic pungency the ills of a contemporary urban lifestyle driven by the mechanistic paradigm of a time-obsessed iron-cage world." (108) Obviamente, yo he puesto un énfasis de lectura muy distinto.

14. Podría haber incluido este sueño entre aquellos que presentan un problema en cuanto a la "sostenibilidad" de su construcción. No lo hago 
porque creo que aquí se trata de construir una metáfora de cómo los seres humanos perseguimos detener el paso del tiempo.

15. En este subapartado, marcaré con asterisco aquellos mundos que, por dar lugar tanto a la posibilidad de vivir felizmente como a la contraria, ya he debido comentar en el subapartado anterior. Seré más breve en su descripción aquí, para evitar las repeticiones innecesarias.

16. No se explica cómo es que no olvidan también el leer, ni se exploran los problemas prácticos que una existencia totalmente desmemoriada plantearía: nadie sabría conducir, nadie podría aprender un oficio, nadie sería capaz de construir una herramienta o de cuidar cabalmente a un niño. Quinto caso en que detecto una debilidad en la narración.

17. Hubiera sido posible incluir este mundo en subapartado anterior, pero no lo hice porque se da a entender que este grupo inconforme con su futuro es una minoría.

18. El Einstein histórico jamás dejó de hacer referencias teológicas. Recuérdese, por ejemplo, la ira que le provocaba la mecánica cuántica porque, según sus palabras, "Dios no juega a los dados", lo que podría inferirse de esa teoría. Y, sólo de pasada, recuérdese también lo que terminó por replicarle Nils Bohr: "Deja de decirle a Dios cómo pensar."

19. La excepción es el sueño del 15 de junio de 1905. Aquí resulta débil que lo que antes se ha juzgado como causa de desdicha (el tiempo que se detiene), ahora se juzgue, sin dar nuevos argumentos, como motivo de lo contrario.

\section{Bibliografía}

Brockman, John (Ed.) 2012. Universo. Traducción de Javier García Sanz. Barcelona: Crítica.
Butler, Jonathan. 2014. "Ecospirituality in the Age of Technological Overkill: BodyTime Reclamation in the Fiction of Alan Lightman and Don DeLillo", Ecozono 2/2 (2011): 100-119. <http://www.ecozona.eu/ index.php/journal/article/view/240/410>.

Goldstein, R. y Lightman, A. 2001. "Bridging the Two Cultures; A Conversation between Rebecca Goldstein and Alan Lightman", World Literature Today 85/1 (2001). <http://www.worldliteraturetoday. org/2011/january/bridging-two-culturesconversation-between-alan-lightman-andrebecca-newberger\#.VCG1wpSSxzp>.

Lightman, Alan. 2014. "El físico como novelista", Revista Eureka sobre Enseñanza $y$ Divulgación de las ciencias 2/002 (2005): 155-162. <http://www.redalyc.org/ pdf/920/92020203.pdf $>$.

Lightman, Alan. 1993. Einstein's Dreams. Vintage ebooks.

The Crossroads of Science and the Arts by Dr. Alan Lightman. GT Honors Program. (video) <https://www.youtube.com/ watch? $=$ cTFYIwqhPXQ $>$ (30 sept. 2014)

Rees, Martin. 2001. Antes del principio. El cosmos y otros universos. Traducción de Nestor Herrán. Barcelona: Tusquets Editores.

Wallhead, Celia M. 2005. "The Human Side of Science in the novels of Alan Lightman", Revista Canaria de Estudios Ingleses 50: 181-199. <http://publica.webs.ull.es/ upload/REV\%20RECEI/50\%20-\%20 2005/13\%20(Celia\%20M_\%20Wallhead). pdf $>(1$ sept. 2014).

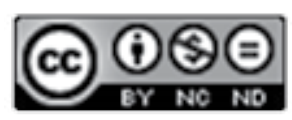

Esta obra está bajo una licencia de Creative Commons Reconocimiento-NoComercial-SinObraDerivada 4.0 Internacional. 